COMUNICAÇÃO CIENTÍFICA

\title{
APLICAÇÃO DE ETHEPHON NO RALEIO QUÍMICO DE AMEIXEIRA E SEU EFEITO SOBRE A PRODUTIVIDADE ${ }^{1}$
}

\author{
ALEXANDRE POZZOBOM PAVANELLO² \& RICARDO ANTONIO AYUB ${ }^{3 *}$
}

RESUMO - O raleio promove aumento no tamanho dos frutos, equilíbrio entre o crescimento vegetativo e produtivo e evita alternância da produção. O objetivo deste trabalho foi avaliar o efeito de diferentes concentrações de ethephon no raleio químico da ameixeira cv. Irati, com 4 anos de idade, sobre o porta-enxerto A-9, em espaçamento 5,0 x 2,5 m, no município de Arapoti - PR. Os tratamentos foram cinco concentrações de ethephon, 0,$1 ; 0,125 ; 0,15 ; 0,2 \mathrm{mg} \mathrm{L}^{-1}$, aplicados 30 dias após a plena florada. As seguintes características foram avaliadas: número médio de frutos por ramo, número total de frutos na colheita, produção por planta, peso médio de frutos, diâmetro dos frutos, teor de sólidos solúveis, firmeza, acidez titulável, $\mathrm{pH}$ e coloração. O aumento na concentração de ethephon reduziu linearmente o número de frutos calibre I, calibre II e calibre III, aumentando o número de frutos de calibre IV, frutos maiores, obtidos com a concentração de $0,093 \mathrm{mg} \mathrm{L}^{-1}$ de ethephon. A seca ocorrida entre os meses de agosto e setembro pode ter afetado o bom desenvolvimento dos frutos.

Termos para Indexação: Prunus salicina, ácido 2-cloroetilfosfônico, frutificação.

\section{APPLICATION OF ETHEPHON THINNING IN CHEMICAL PLUM AND ITS EFFECT ON PRODUCTIVITY}

\begin{abstract}
Thinning promotes an increase in fruit size, balance between vegetative growth and productive and prevents switching of production. The aim of this study was to evaluate the effect of different concentrations of ethephon on chemical thinning of plum cv. Irati, at 4 years old on rootstock A-9 spaced $5.0 \times 2.5 \mathrm{~m}$, in the municipality of Arapoti - PR. Five treatments were tested at ethephon concentrations of $0.1 ; 0.125 ; 0.15 ; 0.2 \mathrm{mg} \mathrm{L}^{-1}$, applied 30 days after full bloom. The following characteristics were evaluated: average number of fruits per branch, number of fruits form whole plant at harvest point, yield per plant, fruit weight, fruit diameter, soluble solids, fruit stiffness, acidity, $\mathrm{pH}$ and color. Increased in the concentration of ethephon linearly reduced the number of fruit, I, II and III diameter, increasing the number of fruit of IV diameter, larger fruit, obtained with the concentration of $0.093 \mathrm{mg} \mathrm{L}^{-1}$ of ethephon. The drought in August and September may have affected the smooth fruit development.
\end{abstract}

Index terms: Prunus salicina, 2-chloroethylphosphonic acid, fruit set.

$\mathrm{O}$ raleio promove o aumento no tamanho dos frutos, evita a alternância de produção e quebra de ramos, melhora a qualidade e equilibra o número de frutos em relação à parte aérea, levando ao aumento de assimilados para os frutos e brotos remanescentes (COSTA; VIZZOTTO, 2000; DENNIS, 2000).

O raleio pode ser realizado durante a floração, mas é frequentemente feito mais tarde, após a fixação dos frutos, podendo-se definir melhor a frutificação. $\mathrm{O}$ raleio manual de um grande número de plantas não é prático nem econômico (WERTHEIM, 2000), representando cerca de $30 \%$ das despesas anuais (DUNCAN, 2004), devido à grande utilização de mão de obra.

A alternativa é o raleio químico, o qual consiste na aplicação de produtos químicos na floração ou logo após, provocando a abscisão de frutos, diminuindo ou eliminando a atividade do raleio manual.

Os principais produtos utilizados para o raleio químico de ameixas são ANA (ácido naftalenoacético), ethephon, paclobutrazol e tiossulfato de amônia; entretanto, são aplicados logo após o pleno florescimento, antes de poder verificar se o

\footnotetext{
1(Trabalho 101-11). Recebido em: 23-03-2011. Aceito para publicação em: 06-02-2012.

${ }^{2}$ Mestrando em Agronomia, Bolsista Capes, Universidade Estadual de Ponta Grossa - UEPG, Departamento de Fitotecnia e Fitossanidade, Av. Carlos Cavalcanti, 4748, 84030-900, Ponta Grossa - PR, Brasil. Contato: alexandrepavanello@hotmail.com

${ }^{3}$ Prof PhD. Universidade Estadual de Ponta Grossa - UEPG, Departamento de Fitotecnia e Fitossanidade, Av. Carlos Cavalcanti, 4748, 84030-900, Ponta Grossa - PR, Brasil, Bolsista Produtividade do CNPq. Autor para Contato: rayub@uepg.br*
} 
vingamento de frutos foi satisfatório (WEBSTER; SPENCER, 2000). Entretanto, para macieira, existem raleantes químicos de pós-floração, destacando-se o Carbaryl, Ethephon e a Benziladenina (PETRY, 2011). O raleante químico ideal seria aquele aplicado após a fixação de frutos, que em uma única aplicação causasse a abscisão parcial de frutos, momentos seguintes à aplicação, o qual infelizmente inexiste para ameixeiras. Nas condições brasileiras, não existem trabalhos publicados sobre o raleio químico de ameixeiras.

A ação fisiológica da maioria dos raleantes químicos é desencadear um desequilíbrio entre os fluxos no transporte de auxina, ocasionando abscisão. A auxina, especificamente o AIA (ácido indolilacético), tem efeito em reduzir a sensibilidade da zona de abscisão ao etileno. Na concentração baixa de AIA, o etileno é ativado, resultando em abscisão. O ethephon é um inibidor do transporte de auxina, através da liberação de etileno, ocasionando a queda dos frutos. A aplicação de ethephon promoverá a abscisão de frutos com menores concentrações de AIA (BANGERTH, 2000).

Nesse contexto, o objetivo deste trabalho foi avaliar o efeito de diferentes concentrações de ethephon (ácido 2-cloroetilfosfônico) no raleio químico da ameixeira cv. Irati, na região de Arapoti - PR.

O experimento foi desenvolvido de julho a outubro de 2010, em pomar comercial de ameixeiras cv. Irati, com 4 anos de idade, sobre o porta-enxerto A-9, em espaçamento 5,0 x 2,5 m, conduzidas no sistema de vaso, no município de Arapoti - PR. A altitude do local é de $850 \mathrm{~m}$, e os dados de temperatura média e precipitações acumuladas mensalmente para o ano de 2010 foram mensuradas com termômetro TI 915MHZ e pluviômetro (Figura 1).

Os tratamentos foram cinco concentrações de ethephon, $0 ; 0,1 ; 0,125 ; 0,15$ e $0,2 \mathrm{mg} \mathrm{L}^{-1}$, aplicadas com 700 litros por hectare de volume de calda, 30 dias após a plena florada, verificando-se alta porcentagem de fixação de frutos por ramo (Tabela 1), justificando o experimento. A aplicação nesta fase é interessante, porque se sabe que a fixação de frutos é satisfatória, diferentemente da florada onde há riscos climáticos que podem comprometer a fixação dos frutos. O produto comercial utilizado foi Ethrel 240® (Bayer) e o pulverizador utilizado para aplicação foi Montana com 1.500L. A quebra de dormência foi realizada no dia 15 de junho, a plena florada foi no dia 10 de julho, com alta intensidade de florescimento, e a aplicação dos tratamentos, dia 07 de agosto. A colheita foi realizada no dia 16 de outubro.

As seguintes características foram avaliadas: número de frutos por ramo, com contagem de 20 ramos por planta de aproximadamente $30 \mathrm{~cm}$, antes da aplicação dos tratamentos e 45 dias após, número total de frutos na colheita, produção por planta e peso médio dos frutos, obtido pela divisão do número total de frutos por planta sobre a produção por planta. O diâmetro dos frutos foi determinado com paquímetro, sendo feita a classificação dos frutos por tamanho, em que o Calibre I corresponde ao diâmetro de 2,5 a 3,0 cm, Calibre II, 3,0 a 3,5 cm, Calibre III, 3,5 a $4,0 \mathrm{~cm}$ e Calibre IV, 4,0 a 4,5 cm.

O teor de sólidos solúveis foi determinado com refratômetro manual, modelo Digit, expresso em ${ }^{\circ}$ Brix. A firmeza foi determinada com auxílio de penetrômetro marca Instrutherm DD - 200, com ponteira de $8 \mathrm{~mm}$ de diâmetro, sendo as medidas realizadas com remoção de pequena porção da casca na região equatorial do fruto, e os valores, expressos em Newtons. A acidez titulável foi determinada por titulação com hidróxido de sódio, $\mathrm{NaOH} 0,1 \mathrm{~N}$, até pH 8,1 de 10 mL de suco diluído em 100 mL de água destilada, expresso em porcentagem de ácido málico. $\mathrm{O}$ pH foi medido com pHmetro digital marca Quimis.

A coloração superficial foi determinada pela medida dos parâmetros L, a e b com colorímetro (Minolta CR400®, Osaka, Japão) e a partir de dados dessas determinações, calculou-se o ângulo hue como sendo ${ }^{\circ} \mathrm{h}=\tan (\mathrm{b} / \mathrm{a})$, quando $\mathrm{a}>0$ e $\mathrm{b}>0$ ou como ${ }^{\circ} \mathrm{h}=180^{\circ}-\tan (\mathrm{b} / \mathrm{a})$ quando $\mathrm{a}<0$ e $\mathrm{b}>0$. O ângulo hue mostra a localização da cor, em que o ângulo $0^{\circ}$ representa vermelho puro, $90^{\circ}$ representa o amarelo puro, $180^{\circ}$ o verde puro e o $270^{\circ}$ o azul (LANCASTER et al., 1997).

$\mathrm{O}$ delineamento experimental foi em blocos ao acaso, com 5 tratamentos, 4 repetições, 5 plantas por parcela experimental, da qual se avaliou a planta do meio. Os resultados foram submetidos à análise de variância e regressão polinomial $(\mathrm{p}<0,05)$. Para as análises estatísticas, foi utilizado o software SISVAR.

O número de frutos, após 45 dias da aplicação dos tratamentos, reduziu linearmente com o aumento na concentração de ethephon (Figura 2).

$\mathrm{O}$ aumento na concentração de ethephon reduziu linearmente o número de frutos calibre I, calibre II e calibre III (Figuras 3; 4 e 5). Já os frutos maiores, de calibre IV, aumentaram com a concentração de 0,093 $\mathrm{mg} \mathrm{L}^{-1}$ de ethephon (Figura 6). Este resultado é coerente, pois com a intensificação do raleio, há redução do número de frutos por planta, com consequente aumento no calibre dos mesmos. O menor número de frutos, de calibre I, II e III, reduz o custo de colheita e a classificação, podendo ainda dispensar o raleio manual, menor uso de embalagens e menor espaço utilizado no armazenamento, reduzindo o custo do transporte e aumentando a renta- 
bilidade para o agricultor. A seca ocorrida entre os meses de agosto e setembro (Figura 1) afetou o bom desenvolvimento dos frutos, reduzindo o número de frutos por planta (Figura 7), a produção (Figura 8) e o peso médio dos frutos (Figura 9).

O raleio químico reduziu linearmente o número de frutos por planta e a produção. Ao contrário do esperado, o peso médio dos frutos reduziu-se da mesma forma com o aumento da concentração de ethephon. Isto pode ter sido efeito da seca ocorrida na fase de enchimento do fruto.

$\mathrm{O}$ aumento na concentração de ethephon reduziu linearmente a firmeza dos frutos (Figura 10). A testemunha apresentou 27,72 N de firmeza, já a cv. Golf Blaze também precoce $31,14 \mathrm{~N}$, segundo Barbosa (2006), e as cvs. tardias, Reubennel com firmeza de 30,1 N, Pluma 7 com 31,9 N (BRACKMANN et al., 2005) e Laetitia com 36,4 N (ARGENTA et al., 2011). Com isso, a cv. Irati apresenta resultados semelhantes às cultivares citadas; entretanto, nos tratamentos com a aplicação de ethephon, a firmeza reduziu em média para $18,16 \mathrm{~N}$, apresentando frutos menos firmes.

Os sólidos solúveis, a acidez titulável e o pH não foram afetados pelo raleio químico. $\mathrm{A} \mathrm{cv}$. Irati apresentou, em média, 9,53 ${ }^{\circ}$ Brix, 0,12\% de ácido málico e $\mathrm{pH} 3,0$, mostrando qualidade de fruto inferior à cv. Golf Blaze, que apresenta em média 12 a 13 ${ }^{\circ}$ Brix e pH 3,1 a 3,9 (BARBOZA, 2006; CHAGAS, 2008), a Reubennel com 12 a $15,3{ }^{\circ}$ Brix e o pH 3,02 (BRACKMANN et al., 2005; CHAGAS, 2008) .

A coloração foi beneficiada pelo uso do ethephon (Figura 11), pois a cor vermelha foi intensificada com o aumento na concentração do mesmo. A testemunha apresentam ângulo hue de 24,5; e os tratamentos com ethephon, um ângulo hue médio de 19,06. Este fato está em concordância com resultados obtidos por Chagas (2008), com ângulo hue de 22,16 para cv. Golfblaze. Isto se deve à maior degradação de clorofila promovida pelo etileno (PECH et al., 2008).

Neste contexto, podemos concluir que o aumento na concentração de ethephon diminuiu linearmente o número de frutos de calibre I, II e III; já o calibre IV apresentou o maior número de frutos na concentração de $0,093 \mathrm{mg} \mathrm{L}^{-1}$ de ethephon. Os tratamentos com ethephon apresentaram menor firmeza em comparação à testemunha, e nenhuma das concentrações de ethephon afetou a qualidade físico química dos frutos em relação ao teor de sólidos solúveis, $\mathrm{pH}$ e acidez, mas melhoraram a coloração dos mesmos.

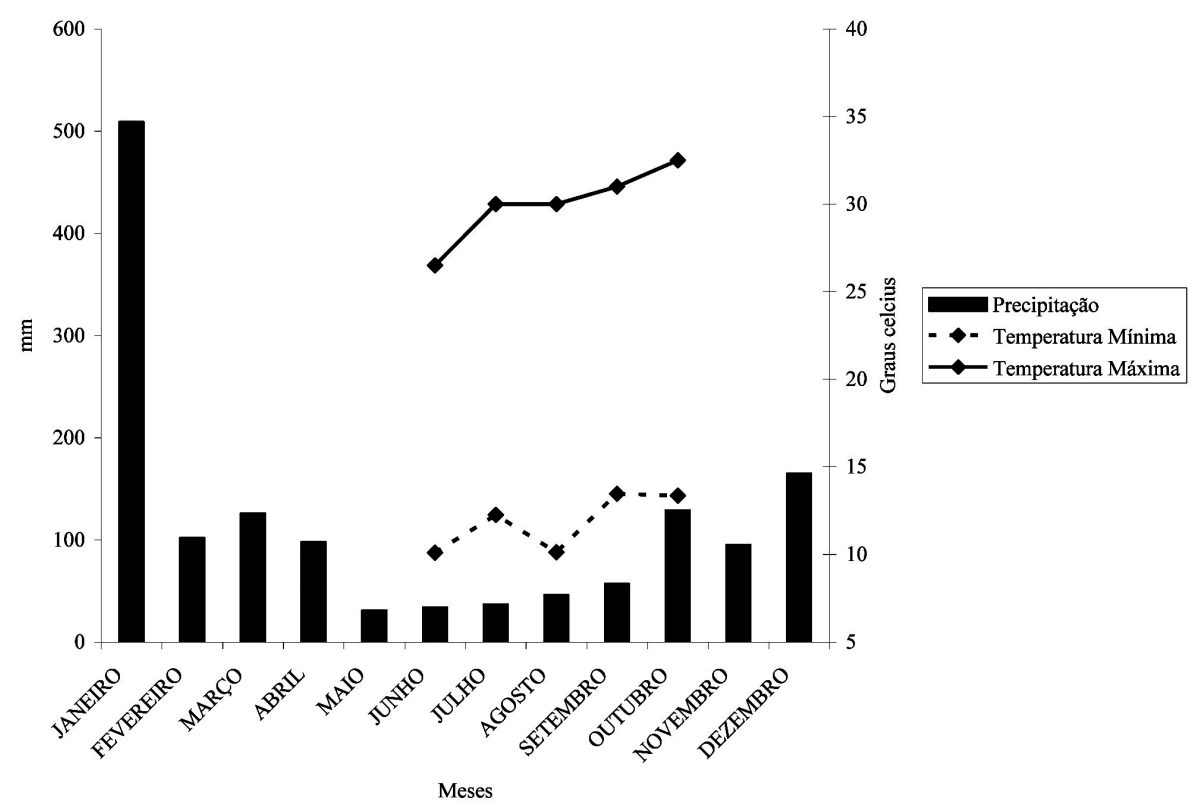

FIGURA 1 - Temperatura média mensal, mínima e máxima $\left({ }^{\circ} \mathrm{C}\right)$, e precipitação acumulada $(\mathrm{mm})$, no ano de 2010. 
TABELA 1 - Número médio de frutos, por ramo de aproximadamente $30 \mathrm{~cm}$, de ameixeira cv. Irati, antes da aplicação dos tratamentos nas diferentes parcelas (Arapoti - PR, 2010).

\begin{tabular}{|c|c|}
\hline TRATAMENTOS & NÚMERO MÉDIO DE FRUTOS POR RAMO $(+-30 \mathrm{~cm})$ \\
\hline Parcela 1 & 26,5 \\
\hline Parcela 2 & 36,75 \\
\hline Parcela 3 & 23,5 \\
\hline Parcela 4 & 32,5 \\
\hline Parcela 5 & 30 \\
\hline
\end{tabular}

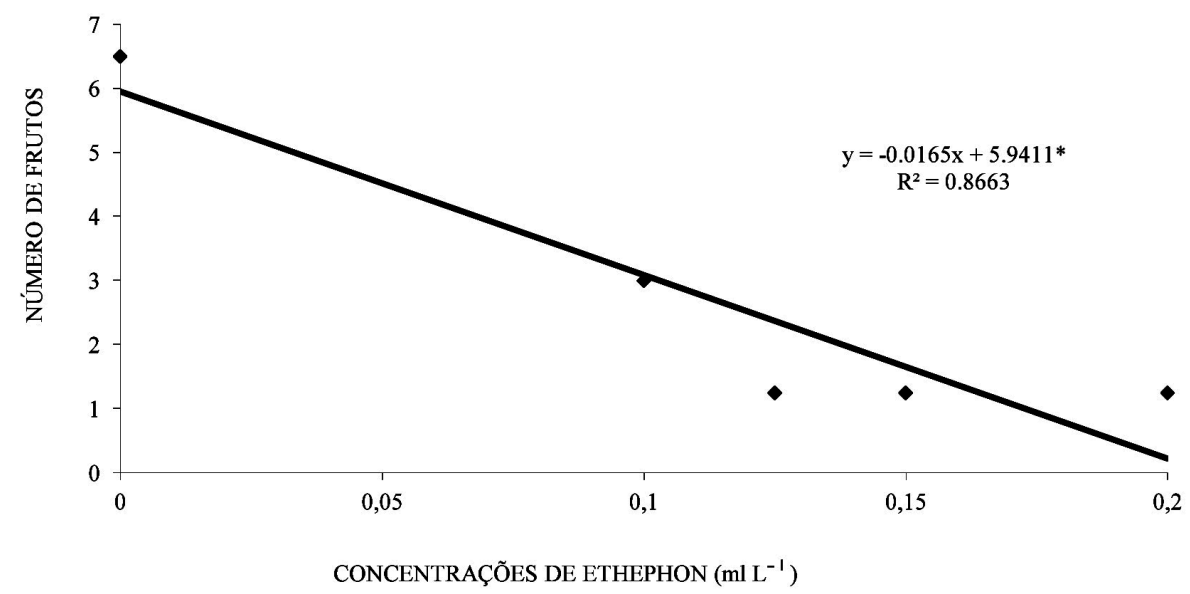

FIGURA 2 - Número médio de frutos por ramo de ameixeira cv. Irati, aos 45 dias após aplicação de diferentes concentrações de ethephon (Arapoti - PR, 2010).

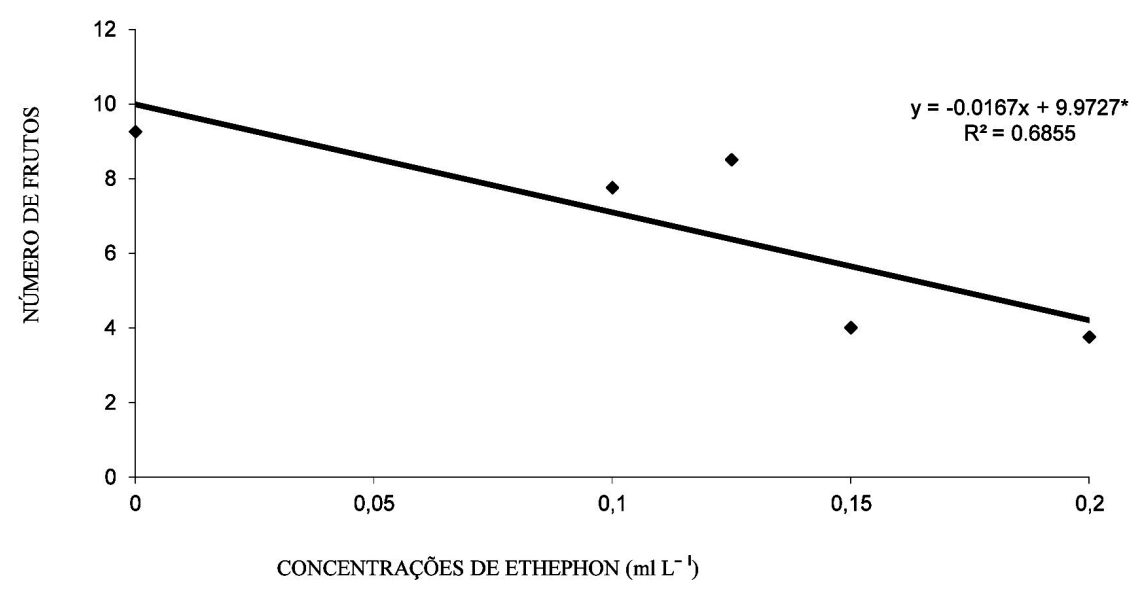

3 - F.feito da concentracão de ethenhon sohre n númern de frutos Calihre I de ameixeira

FIGURA 3 - Efeito da concentração de ethephon sobre o número de frutos Calibre I de ameixeira cv. Irati. (Arapoti-PR, 2010). 


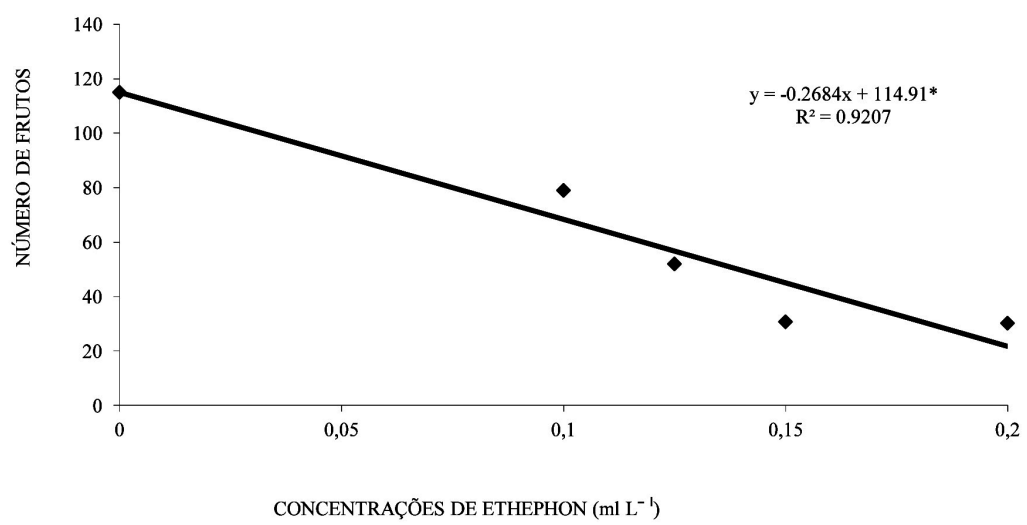

FIGURA 4 - Efeito da concentração de ethephon sobre o número de frutos por planta Calibre II de ameixeira cv. Irati. (Arapoti - PR, 2010).

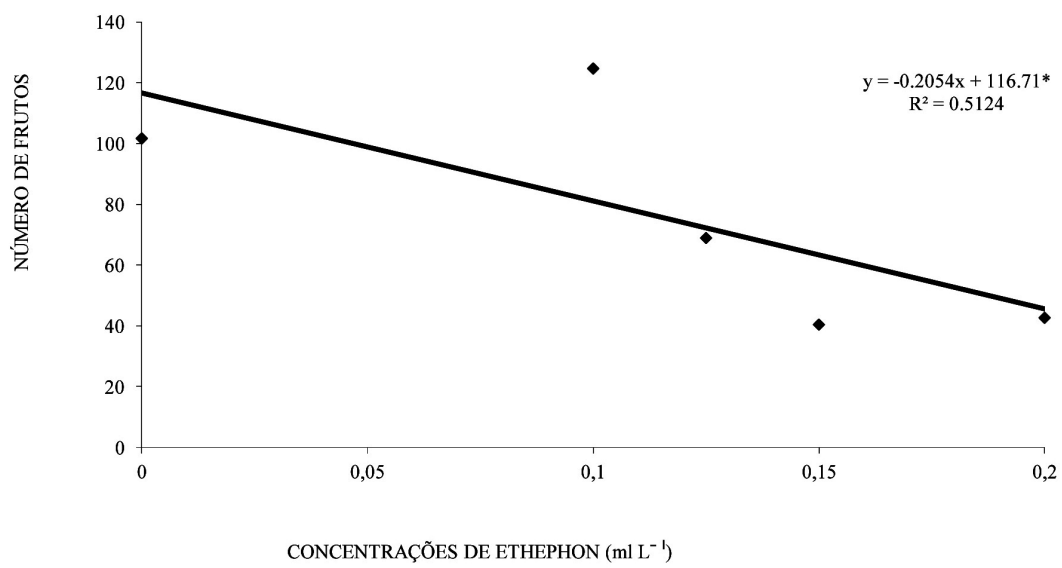

FIGURA 5 - Efeito da concentração de ethephon sobre o número de frutos Calibre III de ameixeira cv. Irati. (Arapoti - PR, 2010).

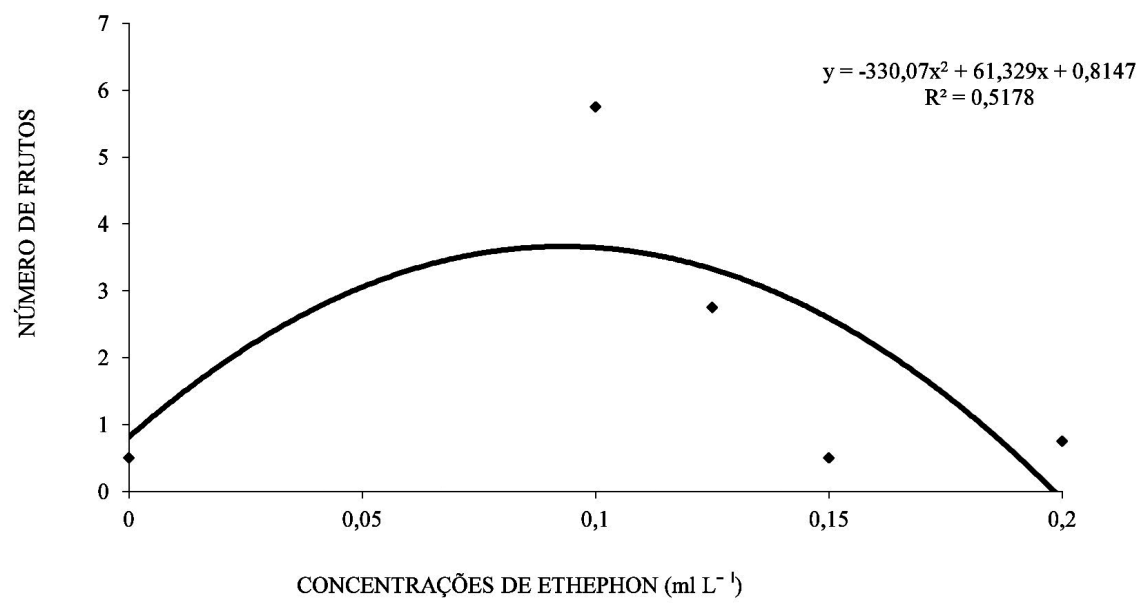

FIGURA 6 - Efeito da concentração de ethephon sobre o número de frutos Calibre IV de ameixeira cv. Irati. (Arapoti - PR - 2010). 


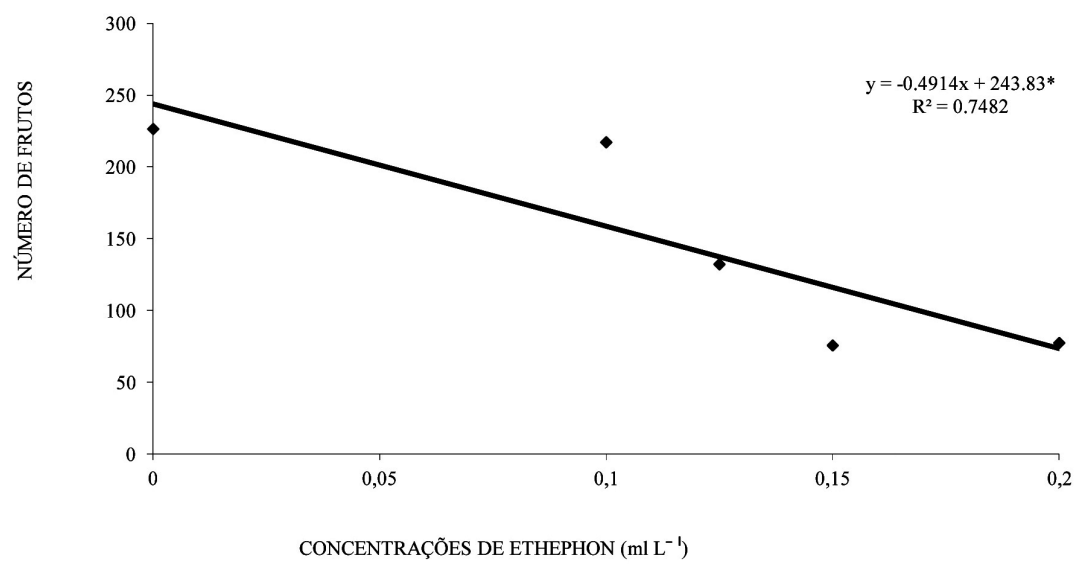

FIGURA 7 - Efeito da concentração de ethephon sobre o número de frutos por planta de ameixeira cv. Irati. (Arapoti - PR - 2010).

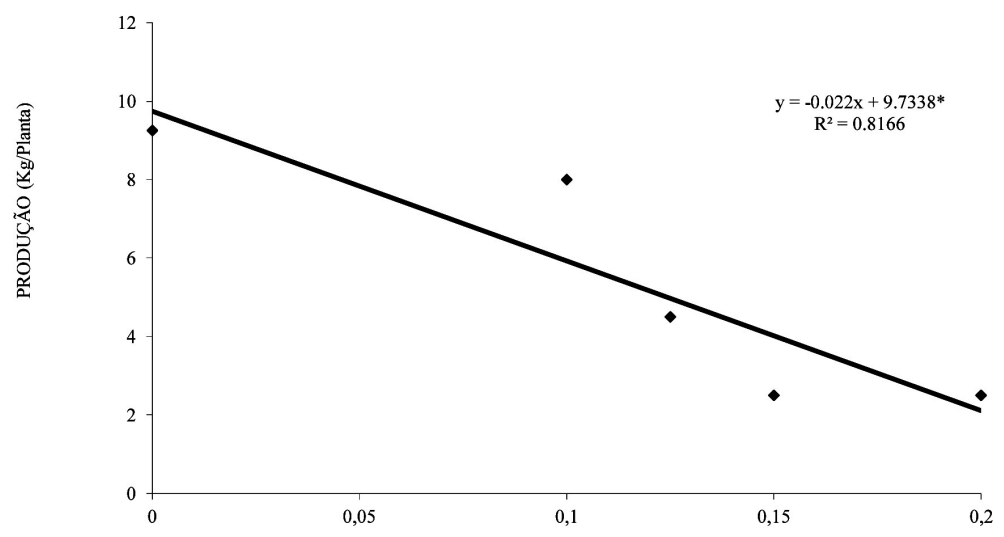

CONCENTRAÇÕES DE ETHEPHON $\left(\mathrm{ml} \mathrm{L}^{-1}\right)$

FIGURA 8 - Efeito da concentração de ethephon na produção por planta de frutos de ameixeira cv. Irati. (Arapoti - PR - 2010).

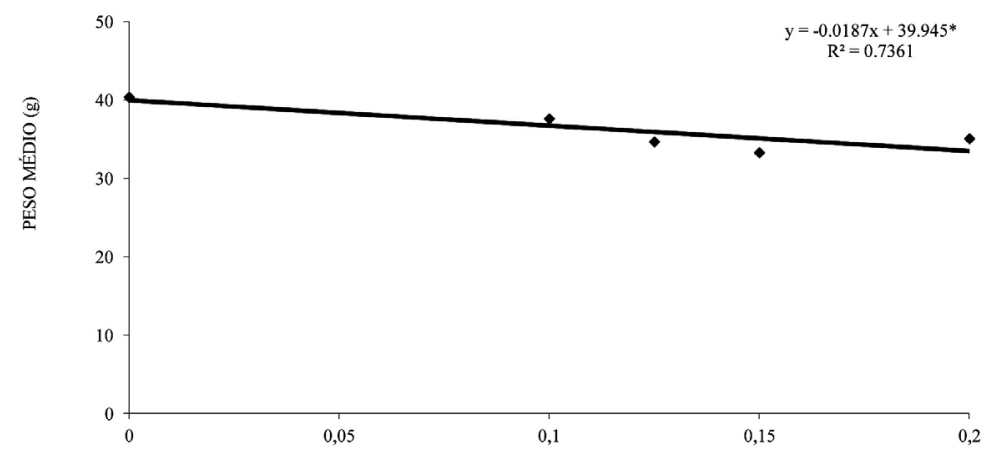

FIGURA 9 - Efeito da concentração de ethephon sobre o peso médio de frutos de ameixeira cv.Irati. (Arapoti - PR/2010.) 


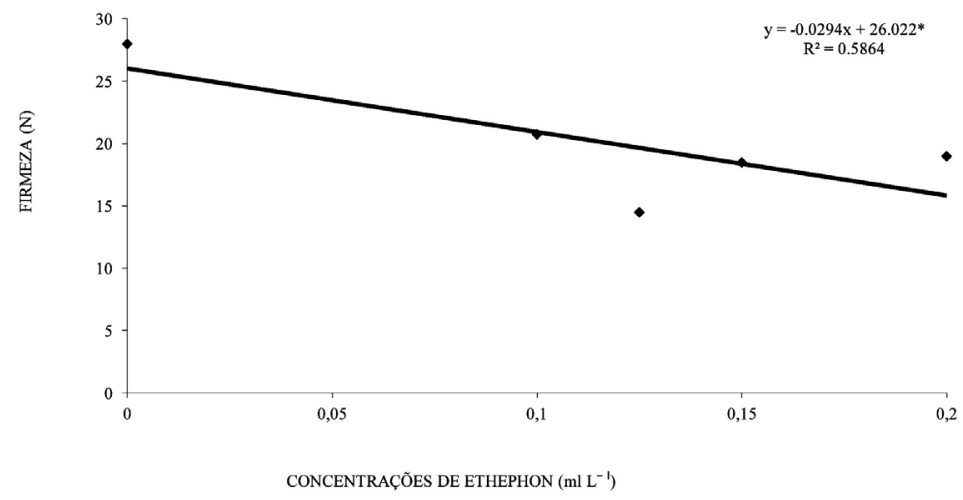

FIGURA 10 - Efeito da concentração de ethephon na firmeza dos frutos de ameixeira cv. Irati. (Arapoti PR - 2010).

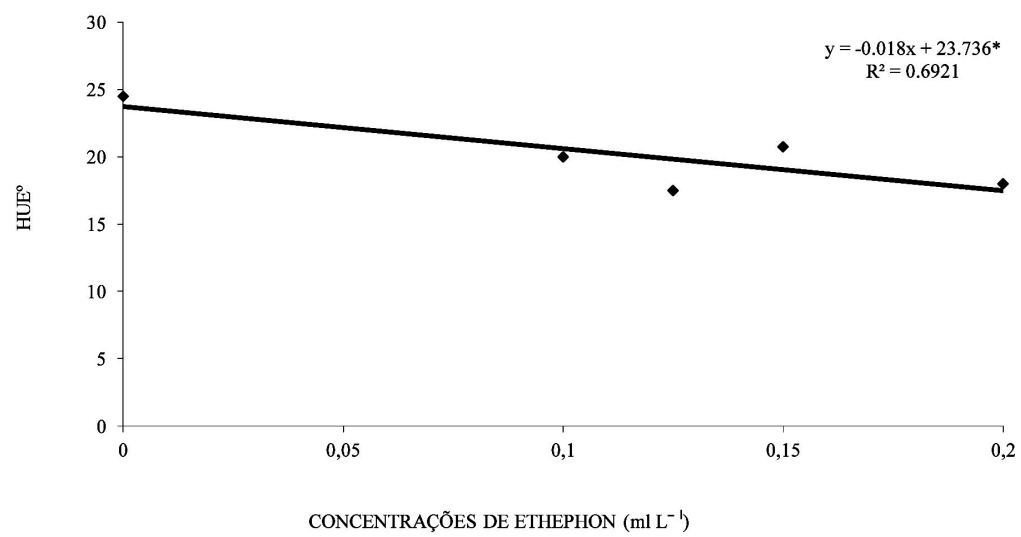

FIGURA 11 - Efeito da concentração de ethephon na coloração dos frutos de ameixeira cv. Irati. (Arapoti $-\mathrm{PR}-2010)$.

\section{REFERÊNCIAS}

ARGENTA, C. A.; AMARANTE, C. V. T.; SHIRAYAMA, D.; SCOLARO, A. M. T.; AYUB, R. A. Controle do escurecimento interno de ameixas durante o armazenamento pelo manejo do ponto de colheita e do etileno. Revista Brasileira de Fruticultura, Jaboticabal, v.33, n.2, p.376-385, 2011.

BANGERTH, F. Abscission and thinning of young fruit and their regulation by plant hormones and bioregulators. Plant Growth Regulation, Dordrecht, v. 31, p. $43-59,2000$.

BARBOSA, W. Comportamento da cv. -GolfBlaze(Fla 87-7) no Estado de São Paulo. Gulfblaze: nova opção de ameixa para o Estado de São Paulo. 2006. Disponível em: $<$ http://www.infobibos.com/Artigos/ Ameixa/Ameixa.htm>. Acesso em: 10 fev. 2011.
BRACKMANN, A.; BENEDETTI, M.; HUNSCHE, M.; SESTARI, I.; Armazenamento de ameixas cvs. Reubennel e pluma 7 sob diferentes temperaturas, em atmosfera controlada e refrigerada. Revista Brasileira deAgrociência, Pelotas, v.11, n. 1, p. 85-89, 2005.

CHAGAS, P. C. Cultivares de ameixa de baixa exigência em frio para regiões subtropicais do Estado de São Paulo. 2008. 123 f.. Dissertação (Mestrado em Fitotecnia) - Escola Superior de Agricultura 'Luiz de Queiroz', Universidade de São Paulo, Piracicaba, 2008.

COSTA, G.; VIZZOTTO, G. Fruit thinning of peach trees. Plant Growth Regulation, Dordrecht, v. 31, p. 113-119, 2000. 
DENNIS, F. G. The history of fruit thinning. Plant Growth Regulation. Dordrecht, v. 31, p. 1-16, 2000. DUNCAN, R. Chemical blossom thinning of peaches. Pomology Farm advisor, UC Cooperative Extension, Stanislaus Country, 2004. Disponivel em: $<$ http://cestanislaus.ucdavis.edu/files/40396.pdf $>$. Acesso em: 25 jan. 2011.

LANCASTER, J.E.; LISTER, C.E.; READY, P.F.; TRIGGS, C.M. Influence of pigment composition on skin color in a wide range of fruit and vegetables. Journal of the American Society of Horticultural Science, Alexandria, v.122, p.594-598, 1997.

PECH, J.C.; BOUZAYEN, M.; LATCHÉ, A. Climateric fruit ripening: Ethylene-dependent and independent regulation of ripening pathways in melon fruit. Plant Science, Limerick, v. 175, n.1-2, p. 114-120, 2008.
PETRI, J. L.; LEITE, G. B.; HAWERROTH, F. J. Raleio em Pós-Floração na Macieira. In: ENFRUTE - ENCONTRO NACIONAL SOBRE FRUTICULTURA DE CLIMA TEMPERADO, 12., 2011. Fraiburgo. Anais... .Fraiburgo: EPAGRI, 2011. p 103.

WEBSTER, A.D.; SPENCER, J.E. Fruit thinning plums and apricots. Plant Growth Regulation, Dordrecht, v. 31, p. 101-112, 2000.

WERTHEIM, S. J. Developments in the chemical thinning of Apple and pear. Plant Growth Regulation, Dordrecht, v. 31, p. 85-100, 2000. 